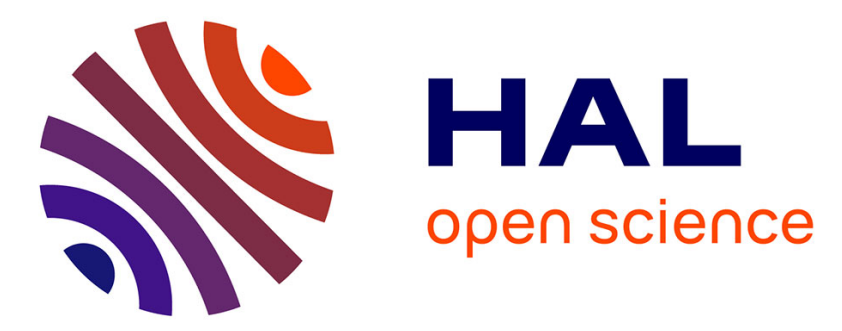

\title{
Validity and reliability of the MSKCC Bowel Function Instrument in a sample of Italian rectal cancer patients
}

P. Zotti, P. del Bianco, S. Serpentini, P. Trevisanut, M.C. Barba, V. Valentini, A. de Paoli, S. Pucciarelli

\section{- To cite this version:}

P. Zotti, P. del Bianco, S. Serpentini, P. Trevisanut, M.C. Barba, et al.. Validity and reliability of the MSKCC Bowel Function Instrument in a sample of Italian rectal cancer patients. EJSO - European Journal of Surgical Oncology, 2011, 10.1016/j.ejso.2011.04.002 hal-00710922

\section{HAL Id: hal-00710922 \\ https://hal.science/hal-00710922}

Submitted on 22 Jun 2012

HAL is a multi-disciplinary open access archive for the deposit and dissemination of scientific research documents, whether they are published or not. The documents may come from teaching and research institutions in France or abroad, or from public or private research centers.
L'archive ouverte pluridisciplinaire HAL, est destinée au dépôt et à la diffusion de documents scientifiques de niveau recherche, publiés ou non, émanant des établissements d'enseignement et de recherche français ou étrangers, des laboratoires publics ou privés. 


\section{Accepted Manuscript}

Title: Validity and reliability of the MSKCC Bowel Function Instrument in a sample of Italian rectal cancer patients

Authors: P. Zotti, P. Del Bianco, S. Serpentini, P. Trevisanut, M.C. Barba, V. Valentini,

A. De Paoli, S. Pucciarelli

PII: $\quad$ S0748-7983(11)00248-4

DOI: $\quad$ 10.1016/j.ejso.2011.04.002

Reference: YEJSO 3147

To appear in: European Journal of Surgical Oncology

Accepted Date: 11 April 2011

Please cite this article as: Zotti $P$, Del Bianco P, Serpentini S, Trevisanut P, Barba MC, Valentini V, De Paoli A, Pucciarelli S. Validity and reliability of the MSKCC Bowel Function Instrument in a sample of Italian rectal cancer patients, European Journal of Surgical Oncology (2011), doi: 10.1016/ j.ejso.2011.04.002

This is a PDF file of an unedited manuscript that has been accepted for publication. As a service to our customers we are providing this early version of the manuscript. The manuscript will undergo copyediting, typesetting, and review of the resulting proof before it is published in its final form. Please note that during the production process errors may be discovered which could affect the content, and all legal disclaimers that apply to the journal pertain. 
Validity and reliability of the MSKCC Bowel Function Instrument in a sample of Italian rectal cancer patients

\section{Running head}

The MSKCC-I bowel function instrument

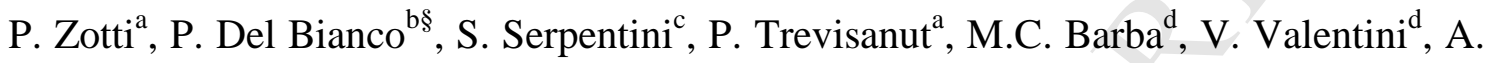
De Paoli ${ }^{\mathrm{e}}$, S. Pucciarelli ${ }^{\mathrm{c}}$

${ }^{a}$ Department of Clinical-Specialty Services \& Support, National Cancer Institute CRO, Aviano, Italy

${ }^{\mathrm{b}}$ Clinical Trials and Biostatistics Unit, Istituto Oncologico Veneto IOV - IRCCS, Padova, Italy

${ }^{c}$ Department of Oncological and Surgical Sciences, Clinica Chirurgica II, University of Padova, Italy

${ }^{\mathrm{d}}$ Department of Radiation Therapy, Università Cattolica del Sacro Cuore, Roma, Italy

e Department of Radiation Therapy and Imaging Diagnostics, National Cancer Institute CRO, Aviano, Italy

${ }^{\S}$ Corresponding author

Paola Del Bianco

Servizio Sperimentazioni Cliniche e Biostatistica

Istituto Oncologico Veneto IOV - IRCCS

via Gattamelata, 64

35128 Padova, Italy 
Phone: +39-049-8215704

Fax: +39-049-8215706

e-mail: paola.delbianco@ioveneto.it

Note: PZ and PDB contributed equally to this work 


\section{Abstract}

\section{Aims}

The purpose of this study was to translate the Memorial Sloan Kettering Cancer Centre (MSKCC) Bowel Function Instrument into Italian and to test its psychometric validity and reliability in a sample of Italian rectal cancer patients.

\section{Methods}

The MSKCC questionnaire was translated into Italian using a standard procedure of double-back translation. Construct validity was tested using a factor analysis and internal reliability was estimated using the Cronbach's alpha coefficient. Concurrent validity was determined by correlations with European Organization for Research and Treatment of Cancer QLQ-C30 and QLQ-CR38 quality of life scales. A non-parametric analysis of variance was used to establish the discriminant validity of the questionnaire. Test-retest reliability was assessed using the intra-class correlation coefficient.

\section{Results}

124 rectal cancer patients participated in the validation study. The number of missing items was $2.2 \%$. The factorial structure was found to be quite similar to the original one and the internal reliability was 0.7 for urgency, 0.6 for frequency, and 0.7 for dietary subscale. The test-retest reliability was acceptable with one exception: the dietary subscale showed a low reproducibility $(\mathrm{ICC}=0.4$ ). All three subscales showed a significant correlation with the QLQ-C30 and QLQ-CR38 domains and were able to discriminate several groups of clinical relevance.

\section{Conclusions}

The Italian version of the MSKCC Bowel Function Instrument shows acceptable psychometric properties and can be considered a valuable and specific instrument to assess bowel functions in rectal cancer patients, both for research purposes and in clinical practice. 
Key words: assessment; bowel function; rectal cancer; validation; questionnaire; quality of life. 


\section{Introduction}

Chemo-radiotherapy, followed by total mesorectal excision, is currently accepted as standard treatment for locally advanced rectal cancer [1,2]. With such treatment, the estimated 5-year survival rate is about $70 \%$, with a local recurrence rate less than $10 \%$. Sphincter-preserving surgery is normally performed in more than $70 \%$ of patients. Compared to surgery alone, however, this approach is associated with increased male sexual problems, faecal incontinence, and bowel dysfunction, which, in turn, negatively affect the quality of life of patients $[3,4]$.

With increasing patient survival, the evaluation of long-term results related to the patient's reported outcomes (quality of life, bowel function, faecal continence, and sexual dysfunction) is clinically relevant. Such findings can be used to better inform the patient and address disease management.

Bowel function is usually investigated with ad hoc questions regarding bowel movements per day, sensation of incomplete evacuation, use of pads, stool fractionation, urgency, use of medication, and occurrence of soiling. However, to date, no standard selfreported questionnaires have been used to evaluate bowel function outcomes after surgery for rectal cancer.

Recently, Temple et al. [5] developed and validated an 18-item self-reported questionnaire to assess bowel function in patients after sphincter-preserving surgery for rectal cancer. To the best of our knowledge, the questionnaire is the only questionnaire available in the literature and is published in English.

The aim of this study was to translate the Memorial Sloan Kettering Cancer Centre (MSKCC) instrument into Italian and to test the psychometric validity of the questionnaire. Our primary goal is to provide an instrument that can be used both for research purposes and in clinical practice. 


\section{Methods}

\section{Patients}

A total of 128 patients with stage II-III [6] rectal cancer, who underwent sphincterpreserving surgery between 2006 and 2007, were recruited from three Italian institutions.

Consecutive patients attending the follow-up visit were included in the study if they had undergone sphincter-preserving surgery with curative intent (R0 resection), were stoma-free at the time of questionnaire completion, aged 18 years or older, and were able to understand and complete the questionnaires. Patients were excluded if they had evidence of cancer recurrence, were currently receiving chemo-radiotherapy, or refused to participate in the study.

The study was approved by the local ethics committee, and all patients gave written informed consent.

Socio-demographic and clinical data were collected from clinical records or directly from the patients.

A test-retest reliability study was carried out on the first 40 patients who agreed to complete the questionnaire again, between 7 and 14 days after the first assessment.

\section{Questionnaires}

Development of the Italian version of the MSKCC questionnaire

The MSKCC Bowel Function questionnaire is a self-administered psychometric instrument designed to assess bowel function in patients who undergo sphincter-preserving surgery for rectal cancer. The questionnaire includes 18 items involving three subscales (frequency, dietary and urgency/soilage), four individual items of clinical significance (Q4: incomplete emptying after a bowel movement, Q6: a second bowel movement within 15 
minutes, Q7: knowing difference between gas and bowel movements, Q12: unable to control the passage of flatus) and one total score that is obtained by summing all 18 items.

The frequency subscale is scored by adding items Q1, Q5, Q8, Q9, Q10 and Q11; the dietary subscale is scored by adding items Q2, Q3, Q13 and Q14; and the urgency subscale is scored by adding items Q15, Q16, Q17 and Q18.

The responses are given on a 5-point Likert scale for all items, apart from the item asking for the frequency of bowel movements. Items Q1, Q4, Q5, Q7, Q11 and Q12 have been recoded so that higher scores indicate better bowel function.

The Italian version of the MSKCC questionnaire (see Appendix) was developed by translating the questions into Italian using the standard procedure of double-back translation between independent translators. The Italian questionnaire was then administered to 10 patients to verify the adequacy and degree of comprehension of the questions (pilot study).

In the original English version, the construct validity of the MSKCC instrument was investigated by comparing the instrument to the European Organization for Research and Treatment of Cancer (EORTC) QLQ-C30 and the Colorectal Cancer module QLQ-CR38 health related quality of life questionnaires. The same instruments, available in Italian, were also administered in this study.

\section{EORTC QLQ-C3O}

Patients' health-related quality of life was measured using the multidimensional EORTC QLQ-C30 questionnaire [7]. This is an internationally validated, cancer-specific, health-related quality of life questionnaire, available in Italian, with proven robust psychometric properties. The 30 items in the EORTC QLQ-C30 questionnaire are grouped into five functional scales (physical, role, cognitive, emotional and social), three symptom domains (fatigue, nausea and vomiting and pain), six single items, and one global health 
status scale. The responses are given on a four-point Likert scale for all items, except for two items that represent the global health status which are scored on a seven-point Likert scale.

The scores for all scales were calculated using procedures defined in the EORTC Scoring Manual [8], and range from 0 to 100 following linear transformation. Higher scores in functional and global health status scales indicate a higher level of functioning and a better quality of life, respectively, whereas higher scores in symptom scales indicate a higher symptom level.

\section{EORTC QLQ-CR38}

The EORTC QLQ-C38 was developed for use in colorectal patients [9]. The questionnaire consists of 38 items that are grouped into four functional scales (body image, sexual function, sexual enjoyment and future perspective) and eight symptom scales (micturition problems, gastro-intestinal symptoms, chemotherapy side-effects, defecation problems, male and female sexual problems, stoma related problems and weight loss). The EORTC QLQ-C38 is scored in a manner similar to the EORTC QLQ-C30.

\section{Statistical methods}

Descriptive statistics were used to summarize the baseline socio-demographic and clinical variables.

For psychometric validation, we determined the construct validity, concurrent validity, discriminant validity and test-retest reliability.

Imputation of missing items was performed for each valid questionnaire by replacing these items with the mean score, provided that at least half of the items from the scale were answered. 
Results are reported with 95\% confidence intervals (CI). All P values are two-sided, and a $\mathrm{P}$ value of $<0.05$ is considered statistically significant. Statistical analyses were performed using SAS statistical software (SAS Institute, Cary, NC).

\section{Construct validity}

To test the robustness of the structure and the dimensionality of the instrument, a factor analysis was performed. Factors were extracted with eingenvalues $>1$ on a varimax rotation from principal factoring analysis. The observed factors were compared to the a priori dimensions.

Item to domain correlations were calculated to evaluate the extent to which each item was associated with its domain or with another competing domain. A correlation of 0.3 is considered acceptable. The internal reliability was estimated using the Cronbach's alpha coefficient [10]. A value of 0.7 or greater is considered acceptable.

\section{Concurrent validity}

Concurrent validity was determined by examining the hypotheses that EORTC QLQC30 global health status, physical, role, and social function should positively correlate with bowel function, whereas diarrhoea and constipation should negatively correlate. EORTC QLQ-CR38 functional scales (body image, sexual function, sexual enjoyment and future perspective) should positively correlate with the MSKCC subscales while symptom scales (micturition, gastro-intestinal and defecation problems, and male and female sexual problems) should negatively correlate. To measure correlation, the Pearson coefficient was used.

\section{Discriminant validity}




\section{ACCEPTED MANUSCRIPT}

Discriminant validity was determined using the known-group method [11]. A nonparametric analysis of variance was used for each dimension to verify whether the scales could differentiate between patients according to their clinical variables.

Known groups of primary interest were age, gender, time since surgery, type of surgical procedure, administration of chemo-radiotherapy, stoma closure, technique of rectal reconstruction, and level of anastomosis. Age was dichotomized as the median, time since surgery was considered as $\leq 24$ months or $>24$ months, which is the time when bowel function should begin to stabilize [12], and the level of anastomosis as $<=6 \mathrm{~cm}$ or $>6 \mathrm{~cm}$.

\section{Test-retest reliability}

The temporal stability of the questionnaire was evaluated by calculating the intraclass correlation coefficient (ICC) based on an analysis of variance. Patients were given a repeat questionnaire seven to fourteen days following the initial questionnaire, during which time no changes were expected to occur. Results were considered unchanged with a coefficient $>0.6$ [11]. 


\section{Results}

Out of 128 patients who were asked to complete the questionnaires during the planned follow-up visit, 4 were excluded because they returned the questionnaire unfilled $(n=3)$ or filled out less than $20 \%$ of items $(n=1)$.

The questionnaire completion rate of the 124 patients included in the analyses was good, with 94 patients answering all 18 items and 20 having only 1 missing item. Missing data were more frequent for item 1 , which deals with the number of daily bowel movements (18 out of 124 patients).

Demographic characteristics for the patient cohort are shown in Table 1.

The most common symptoms reported were unable to control the passage of flatus (Q12, 39 patients), use of pads (Q16, 38 patients), another bowel movement within 15 minutes (Q6, 36 patients) and incomplete emptying after bowel movement (Q4, 36 patients).

\section{Construct validity}

Exploratory factor analysis (Table 2) identified three factors (urgency, frequency, and dietary) that explain $64 \%, 19 \%$, and $11 \%$ of variance, respectively (overall percentage of variance explained 94\%).

The factorial structure for the Italian questionnaire was found to be quite similar to the original MSKCC English questionnaire. We found differences in items Q8 (use of drugs), Q10 (loose stool), and Q18 (alterations in lifestyle) that did not show a strong correlation with their original factor. Item Q8, which correlated with the frequency subscale in the original questionnaire, had a moderate correlation with all three factors, probably due to the low percentage of patients reporting this problem $(n=5)$. Item $Q 10$, included in the frequency subscale, showed a higher correlation with the urgency subscale. Item Q18 correlated with the 
frequency subscale, whereas in the original questionnaire this item showed a factor loading less than 0.3 .

Items Q4 (incomplete emptying after bowel movement), Q7 (knowing the difference between gas and a bowel movement), and Q12 (unable to control the passage of flatus) were distributed on the frequency subscale. Item Q6 (another bowel movement within 15 minutes) was distributed on the urgency subscale. These items were maintained individually due to their clinical relevance, which is in accordance with the original English version.

Item Q1, which asks the number of bowel movements over a 24 hour period, was incorporated into the frequency subscale and responses were divided into quintiles.

Cronbach's coefficient values, to evaluate the internal reliability, were 0.7 for the urgency subscale (Q15, Q16, Q17, and Q18), 0.6 for the frequency subscale (Q1, Q5, Q8, Q9, Q10, and Q11), and 0.7 for the dietary subscale (Q2, Q3, Q13, and Q14).

\section{Concurrent validity}

The MSKCC questionnaire demonstrated a good concurrent validity through significant correlations with comparable domains of the EORTC QLQ-C30 and CR38 questionnaires (Table 3). All three subscales showed significant correlations with the EORTC QLQ-C30 global health status, physical, role, social functioning and diarrhoea. There was also significant correlation with body image, future perspective, gastro-intestinal symptoms, and defecation problems in the EORTC QLQ-CR38. Micturition problems were negatively correlated with frequency and urgency subscales. Male sexual problems showed a significant correlation with dietary and urgency subscales, whereas female sexual problems negatively correlated with urgency. No significant correlations were found between all three subscales and constipation, sexual functioning or sexual enjoyment. The total scale correlated with all selected domains except constipation, sexual function and sexual enjoyment. 
The four single items correlated with defecation problems and future perspective. Incomplete evacuation (Q4) moderately correlated with body image and gastro-intestinal symptoms; another bowel movement within 15 minutes (Q6) correlated with role, social functioning, and diarrhoea; ability to differentiate between gas and bowel movement (Q7) and ability to control gas (Q12) correlated with global health status, role, social functioning, body image and gastro-intestinal symptoms.

\section{Discriminant validity}

The known group validity of the MSKCC questionnaire was supported by several group comparisons (Table 4). Patients aged less than 65 years reported significantly lower function for the frequency subscale and the ability to differentiate between gas and bowel movements (Q7). Complete evacuation (Q4) was significantly better for patients who received postsurgery radiotherapy with respect to pre-surgery or no radiotherapy. The type of surgery and the level of anastomosis differentiated patients reporting another bowel movement within 15 minutes (Q6). The urgency subscale was impaired for patients who underwent coloanal resection.

Significant differences were found between individuals who had a temporary stoma and those who did not with respect to the total scale, the frequency and urgency subscales, complete evacuation (Q4), and whether or not the patient had another bowel movement within 15 minutes (Q6).

\section{Test-retest reliability}

A total of 40 patients completed the MSKCC questionnaire again after a median time of 8 days (range: $5-15$ ). 
The intra-class correlation coefficients were good for the frequency and urgency subscales and the total scale $(0.6,0.9$, and 0.7 respectively). The dietary subscale showed a low reproducibility, with a moderate correlation coefficient of 0.4 . 


\section{Discussion}

A major concern with patients who undergo treatment for rectal cancer is related to the consequences of surgery and chemo-radiotherapy on bowel dysfunction, faecal incontinence, and sexual and voiding problems. While validated instruments are available to assess quality of life, faecal incontinence and sexual and voiding problems, bowel function is usually assessed with non-standardized and non-validated ad hoc questions. These type of ad hoc questions make it difficult to compare studies worldwide and negatively affect the ability of physicians to inform patients about the consequences related to the their treatment for rectal cancer.

In order to overcome these issues, Temple et al. [5] developed a specific questionnaire to evaluate bowel function in patients with rectal cancer. The psychometric properties of the questionnaire were assessed in an English spoken cohort of rectal cancer patients who underwent sphincter-preserving surgery. The questionnaire showed good psychometric characteristics and clinical usefulness. However, the questionnaire is available only in English and has not been validated in other non-English cohorts.

This study presents the results of the validity and reliability of the Italian version of the MSKCC bowel function questionnaire.

The patient sample population who completed the questionnaire was representative of the majority of rectal cancer patients in terms of tumour characteristics and treatment received.

The linguistic validation phase was carried out with 10 patients. A total of further 128 patients from three Italian institutions participated in the full psychometric evaluation. We observed a low number of missing answers to the questionnaire, indicating that the questions were comprehensible and the questionnaire well accepted by the patients. 


\section{Construct validity}

The Italian version of the MSKCC questionnaire demonstrated a robust factor structure and internal reliability, with just few items showing a weaker correlation with their own subscale. In spite of this, the three original subscales showed an acceptable internal reliability with Cronbach's coefficients (more than 0.6 for all subscales) and a test-retest reliability satisfactory for frequency and urgency subscales. The dietary subscale alone resulted in a low temporal stability $(\mathrm{ICC}=0.4)$.

We believe that the few discrepancies with the original factorial structure do not constitute a problem in using the original subscales and could be due to differences in the cultural backgrounds, socio-demographics, and clinical characteristics of the American and Italian samples. Compared to patients enrolled by Temple et al. [5], the Italian sampling included patients with more advanced disease, and the majority of patients had received preoperative chemo-radiotherapy. Moreover, this cohort of Italian patients was heterogeneous, since they were enrolled in three different clinical centres, and the median time to bowel continuity was much shorter than that reported by Temple et al. [5].

\section{Concurrent validity}

Our findings also show that the questionnaire has a good concurrent validity. A significant correlation between quality of life and severity of bowel function was found for almost all selected quality of life domains, comparable to those results obtained using the original version of the questionnaire. Similar to the English version, no correlation was found with the constipation scale, sexual function or sexual enjoyment. The lack of correlation with the constipation scale for all the MSKCC domains may be explained by the items addressed in the questionnaire: the questionnaire deals mostly with continence and frequency problems 
rather than with the difficulty to evacuate. Although none of the domains correlated with sexual function, both male and female sexual problem scores increased with increasing bowel dysfunction, suggesting that the instrument was able to detect a problem when it exists.

\section{Discriminant validity}

The MSKCC questionnaire was able to significantly detect differences in bowel function according to many of the considered clinical variables. We also observed a trend $(\mathrm{p}<0.10)$ towards the ability to differentiate patients based on the time to surgery, consistent with the hypothesis that bowel problems improve over time, and based on radiation therapy. No differences however were found for the type of reconstruction, even if J-pouch anastomosis should decrease the frequency of bowel movements. This may be explained, in part, by the low number of patients who received a $J$-pouch anastomosis $(n=15)$.

The four single items were associated with clinical groups of interest, providing that these items were able to identify patients with different bowel functions. Only the ability to control gas (Q12) was not able to distinguish any group, and therefore, the possibility of including this item in the frequency subscale should be considered. Doing so, the frequency subscale would improve its internal reliability (Cronbach's coefficient of 0.7), whereas its discriminant ability would not change. According to their factor loading, we also tried to include the Q6 single item in the urgency subscale and the Q4, Q7, and Q12 single items in the frequency subscale in order to assess whether the subscales would improve in performance. This analysis showed that the reliability and the discriminant validity of these new subscales remained unchanged. Therefore, we recommend maintaining these items individually given their clinical relevance and because they represent the most highly reported side-effects. 


\section{Conclusion}

In conclusion, our findings show that the Italian version of the MSKCC questionnaire contains acceptable psychometric properties and can be considered a valuable and specific instrument to assess intestinal functions in rectal cancer patients.

Future large cross-sectional and longitudinal studies are required to confirm our findings. 


\section{Appendix. MSKCC Bowel Function Instrument - Italian version ${ }^{1}$ \\ VALUTAZIONE DELLA FUNZIONALITÀ INTESTINALE}

1. Nelle ultime quattro settimane, quante volte scarica generalmente in 24 ore? scariche/24 ore

Nelle ultime quattro settimane...

\begin{tabular}{|c|c|c|c|c|c|c|}
\hline & & Sempre & $\begin{array}{c}\text { La maggior } \\
\text { parte delle volte }\end{array}$ & $\begin{array}{l}\text { Qualche } \\
\text { volta }\end{array}$ & Raramente & Mai \\
\hline 2. & $\begin{array}{l}\text { Alcuni cibi solidi aumentano il numero di } \\
\text { scariche in un giorno? }\end{array}$ & $\square$ & $\square$ & $\square$ & $\square$ & $\square$ \\
\hline 3. & $\begin{array}{l}\text { Alcune bevande aumentano il numero di } \\
\text { scariche in un giorno? }\end{array}$ & $\square$ & $\square$ & $\square$ & $\square$ & $\square$ \\
\hline 4. & $\begin{array}{l}\text { Ha avuto la sensazione di avere scaricato } \\
\text { completamente? }\end{array}$ & $\square$ & $\square$ & $\square$ & $\square$ & $\square$ \\
\hline 5. & $\begin{array}{l}\text { Arriva alla toilette in tempo (quando ha lo } \\
\text { stimolo di andare di corpo)? }\end{array}$ & $\square$ & $\square$ & $\square$ & $\square$ & $\square$ \\
\hline 6. & $\begin{array}{l}\text { Ha avuto la necessità di dover scaricare } \\
\text { nuovamente entro } 15 \text { minuti dall'ultima } \\
\text { scarica? }\end{array}$ & $\square$ & $\square$ & $\square$ & $\square$ & $\square$ \\
\hline 7. & $\begin{array}{l}\text { Quando deve scaricare, riesce a distinguere } \\
\text { se si tratta di feci o di gas/aria? }\end{array}$ & $\square$ & $\square$ & $\square$ & $\square$ & $\square$ \\
\hline 8. & $\begin{array}{l}\text { Ha usato farmaci per ridurre il numero di } \\
\text { scariche (medicine come Imodium o } \\
\text { Dissenten)? }\end{array}$ & $\square$ & $\square$ & $\square$ & $\square$ & $\square$ \\
\hline 9. & $\begin{array}{l}\text { Ha avuto diarrea (feci non formate e/o } \\
\text { liquide)? }\end{array}$ & $\square$ & $\square$ & $\square$ & $\square$ & $\square$ \\
\hline 10. & Ha avuto feci tenere e poco formate? & $\square$ & $\square$ & $\square$ & $\square$ & $\square$ \\
\hline 11. & $\begin{array}{l}\text { E' stato in grado di aspettare } 15 \text { minuti da } \\
\text { quando ha percepito lo stimolo a scaricare? }\end{array}$ & $\square$ & $\square$ & $\square$ & $\square$ & $\square$ \\
\hline 12. & E' stato in grado di trattenere l'aria/gas? & $\square$ & $\square$ & $\square$ & $\square$ & $\square$ \\
\hline 13. & $\begin{array}{l}\text { Ha limitato l'uso di alcuni cibi solidi per } \\
\text { tenere sotto controllo le scariche? }\end{array}$ & $\square$ & $\square$ & $\square$ & $\square$ & $\square$ \\
\hline 14. & $\begin{array}{l}\text { Ha limitato l'uso di alcune bevande per } \\
\text { tenere sotto controllo le scariche? }\end{array}$ & $\square$ & $\square$ & $\square$ & $\square$ & $\square$ \\
\hline 15. & $\begin{array}{l}\text { Ha trovato le mutande sporche di feci } \\
\text { durante il giorno? }\end{array}$ & $\square$ & $\square$ & $\square$ & $\square$ & $\square$ \\
\hline 16. & $\begin{array}{l}\text { Ha fatto uso di pannolini, salviette o garze } \\
\text { durante il giorno per evitare di sporcare le } \\
\text { mutande? }\end{array}$ & $\square$ & $\square$ & $\square$ & $\square$ & $\square$ \\
\hline 17. & $\begin{array}{l}\text { Ha trovato le mutande sporche di feci } \\
\text { quando era a letto? }\end{array}$ & $\square$ & $\square$ & $\square$ & $\square$ & $\square$ \\
\hline 18. & $\begin{array}{l}\text { Ha cambiato le sue attività a causa della sua } \\
\text { funzione intestinale? }\end{array}$ & $\square$ & $\square$ & $\square$ & $\square$ & $\square$ \\
\hline
\end{tabular}

${ }^{1}$ The instrument is provided in Italian to facilitate its use in Italian setting. For the original English version, refer to: Temple LK and al, Dis Colon Rectum 2005: 48: 1353-1365 


\section{Acknowledgments}

The authors thank Dr. GL De Salvo (Sperimentazioni Cliniche e Biostatistica, Istituto Oncologico Veneto - IRCCS, Padova), who critically reviewed the study proposal, and all the research coordinators at all the centres who helped in data acquisition, specifically Dr. Paola Toppan and Dr. Elisa Alducci (Sezione di Clinica Chirurgica II, Università di Padova). 


\section{References}

1. Bosset JF, Collette L, Calais G et al. Chemotherapy with preoperative radiotherapy in rectal cancer. N Engl J Med 2006; 355: 1114-1123.

2. Sauer R, Becker H, Hohenberger W et al. Preoperative versus postoperative chemoradiotherapy for rectal cancer. N Engl J Med 2004; 351: 1731-1740.

3. Pucciarelli S, Del Bianco P, Efficace F et al. Health-related quality of life, faecal continence and bowel function in rectal cancer patients after chemoradiotherapy followed by radical surgery. Support Care Cancer 2010; 18: 601-608.

4. Pucciarelli S, Del Bianco P, Toppan P et al. Health-related quality of life outcomes in disease-free survivors of mid-low rectal cancer after curative surgery. Ann Surg Oncol 2008; 15: $1846-1854$.

5. Temple LK, Bacik J, Savatta SG et al. The development of a validated instrument to evaluate bowel function after sphincter-preserving surgery for rectal cancer. Dis Colon Rectum 2005; 48: 1353-1365.

6. AJCC American Joint Committee on Cancer. In Fleming DI, Cooper SJ, Henson ED, et al (ed) AJCC Cancer Staging Manual, 5th ed, Edition Philadelphia: Lippincott-Raven: 1997; 8390.

7. Aaronson NK, Ahmedzai S, Bergman B et al. The European Organization for Research and Treatment of Cancer QLQ-C30: a quality-of-life instrument for use in international clinical trials in oncology. J Natl Cancer Inst 1993; 85: 365-376.

8. Fayers PM, Aaronson NK, Bjordal K et al. The EORTC QLQ-C30 Scoring Manual (2nd Edition). Brussels: European Organization fo Research and Treatment of Cancer 1999.

9. Sprangers MA, te Velde A, Aaronson NK. The construction and testing of the EORTC colorectal cancer-specific quality of life questionnaire module (QLQ-CR38). European 
Organization for Research and Treatment of Cancer Study Group on Quality of Life. Eur J

Cancer 1999; 35: 238-247.

10. Cronbach LJ. Coefficient alpha and the internal structure of tests. Psychometrika 1951; 16: 297-334.

11. Hays RD, Anderson RT, Revicki D. Assessing reliability and validity of measurement in clinical trials. In Staquet MJ, Hays RD, Fayers PM (ed) Quality of life assessment in clinical trials., Edition Oxford: Oxford University Press 1998; 169-182.

12. Neuman HB, Schrag D, Cabral C et al. Can differences in bowel function after surgery for rectal cancer be identified by the European Organization for Research and Treatment of Cancer quality of life instrument? Ann Surg Oncol 2007; 14: 1727-1734. 
Table 1. Characteristics of the study group

\begin{tabular}{lr}
\hline & $\mathbf{N}$ \\
\hline Total patients & 124 \\
\hline Age & $65(26 ; 82)$ \\
Median (range) & $7(0 ; 15)$ \\
\hline Tumour distance from anal verge, cm & \\
Median (range) (N=121) & \\
\hline Time since surgery, months & \\
Median (range) (N=123) & \\
\hline Time to bowel continuity, months & \\
Median (range) (N=66/66) & $31.7(5.5 ; 64)$ \\
\hline Gender & 35 \\
\hline F & \\
M & $80.1 ; 48.8)$ \\
\hline T stage (missing, N=2) & 7 \\
T1-T2 & \\
T3 & \\
T4 & \\
\hline
\end{tabular}

\begin{tabular}{lr}
\hline N stage (missing, $\mathrm{N}=5)$ & 61
\end{tabular}

N1-N2 $\quad 58$

\begin{tabular}{ll}
\hline Radiotherapy (missing, $\mathrm{N}=1)$ & \\
\hline None & 11
\end{tabular}

$\begin{array}{ll}\text { Preoperative } & 92\end{array}$

$\begin{array}{ll}\text { Postoperative } & 20\end{array}$

Chemotherapy (missing, $\mathrm{N}=1$ )

\begin{tabular}{ll}
\hline None & 13
\end{tabular}

$\begin{array}{ll}\text { Preoperative } & 68\end{array}$

$\begin{array}{ll}\text { Postoperative } & 18\end{array}$

Preoperative and postoperative $\quad 24$

\begin{tabular}{ll}
\hline Surgical procedure (missing, $\mathrm{N}=1$ ) \\
\hline Low anterior resection with stapled anastomosis (LAR)
\end{tabular}

LAR with hand sewn colo-anal anastomosis (CAA) 9

\begin{tabular}{lr} 
Trans-anal local excision & 13 \\
\hline
\end{tabular}

\begin{tabular}{ll}
\hline Temporary stoma in the patients' history (missing, $\mathrm{N}=2$ ) & 56
\end{tabular}

Ileostomy $\quad 58$

Colostomy $\quad 8$

Reconstruction technique after LAR/CAA (missing, N=3)

\begin{tabular}{lr}
\hline Straight & 93
\end{tabular}

\begin{tabular}{lr} 
J-pouch & 15 \\
\hline
\end{tabular} 


\begin{tabular}{llrrr}
\hline & & Urgency & Frequency & Dietary \\
\hline Urgency & & & & \\
Q15 & Soil undergarments during day & $\mathbf{0 . 7 5}$ & 0.32 & 0.10 \\
Q16 & Use tissue, napkin, pad during day & $\mathbf{0 . 5 1}$ & 0.21 & 0.16 \\
Q17 & Soil undergarments in bed & $\mathbf{0 . 7 3}$ & 0.14 & 0.08 \\
Q18 & Alter activities because of bowel function & 0.28 & $\mathbf{0 . 4 1}$ & 0.28 \\
Frequency & & & & \\
Q5 & Get to toilet on time & 0.21 & $\mathbf{0 . 4 8}$ & 0.09 \\
Q8 & Use med to decrease number of BM & 0.25 & 0.16 & 0.26 \\
Q9 & Diarrhoea & 0.21 & $\mathbf{0 . 2 9}$ & 0.20 \\
Q10 & Loose stool & $\mathbf{0 . 6 5}$ & 0.28 & 0.26 \\
Q11 & Able to wait 15 minutes for toilet & 0.15 & $\mathbf{0 . 6 4}$ & -0.08 \\
Dietary & & & & \\
Q2 & Type of solid to increase BM & 0.11 & -0.07 & $\mathbf{0 . 4 8}$ \\
Q3 & Type of liquid to increase BM & 0.20 & 0.20 & $\mathbf{0 . 6 7}$ \\
Q13 & Limit types solid to control BM & 0.06 & 0.02 & $\mathbf{0 . 4 7}$ \\
Q14 & Limit types liquid to control BM & 0.10 & 0.11 & $\mathbf{0 . 6 8}$ \\
Single items & & & & \\
Q4 & Totally empty bowels after BM & 0.08 & $\mathbf{0 . 3 5}$ & 0.03 \\
Q6 & Another BM within 15 minutes of last & $\mathbf{0 . 4 1}$ & 0.23 & 0.17 \\
Q7 & BM & & & \\
Q12 & Known difference between gas and BM & 0.14 & $\mathbf{0 . 4 2}$ & 0.07 \\
Eigen value & Control passage of gas & 0.19 & $\mathbf{0 . 6 6}$ & 0.04 \\
\hline & & 2.34 & 2.00 & 1.72 \\
\hline
\end{tabular}


Table 3. Concurrent validity

\begin{tabular}{|c|c|c|c|c|c|c|c|c|}
\hline & Urge & $\mathbf{y}$ & Dietary & Q4 & Q6 & Q7 & Q12 & Total \\
\hline \multicolumn{9}{|l|}{ EORTC QLQ-C30 } \\
\hline Global health status & $45 * * *$ & $0.34 * * *$ & * $0.18^{*}$ & 0.04 & 0.14 & $0.24 * *$ & $0.23 *$ & $0.40 * * *$ \\
\hline Physical Functioning & $0.39 * * *$ & $0.30 * * *$ & $* 0.24 * *$ & -0.04 & 0.16 & 0.16 & $0.21 *$ & $0.37 * * *$ \\
\hline le Functioning & $0.30 * * *$ & $0.33 * * *$ & $* 0.24 * *$ & 0.13 & $0.19 *$ & $0.28 * *$ & $0.25 * *$ & $0.39 * * *$ \\
\hline inctioning & $0.40 * * *$ & $0.34 * * *$ & $* 0.40 * * *$ & * 0.15 & $0.20 *$ & $0.25^{* *}$ & $0.29 * * *$ & $0.49 * * *$ \\
\hline & 0.00 & -0.09 & -0.12 & -0.15 & -0.09 & -0.09 & -0.04 & -0.11 \\
\hline Diarrhoea & $-0.31 *$ & $-0.46 * * *$ & *-0.18* & 0.03 & $-0.30 * *$ & -0.13 & -0.15 & $-0.39 *$ \\
\hline \multicolumn{9}{|l|}{$\begin{array}{l}\text { EORTC QLQ- } \\
\text { CR38 }\end{array}$} \\
\hline Bodv Imaoe & $33^{*}$ & $0.29 * * *$ & * $0.20^{*}$ & $0.19 *$ & 0.14 & $0.25^{* *}$ & $0.25^{* *}$ & $0.38 * * *$ \\
\hline g & 0.13 & 0.14 & -0.09 & 0.10 & -0.01 & -0.02 & $0.24 * *$ & 0.10 \\
\hline $\mathrm{at} \dagger$ & 0.15 & 0.11 & 0.06 & 0.14 & -0.15 & 0.15 & 0.12 & 0.14 \\
\hline Futs & $0.22 *$ & $0.40 * * *$ & * $0.22 *$ & $0.19 *$ & $0.26 * *$ & $0.35 * * *$ & $0.32 * * *$ & $0.41 * * *$ \\
\hline Mictur & $-0.35^{* *}$ & $-0.31 * * *$ & $*-0.15$ & 011 & -0.15 & -0.13 & $-0.21 *-$ & $-0.35 * * *$ \\
\hline Gastro-Intestinal & $-0.22 *$ & $-0.28 * *$ & $-0.27 *$ & $-0.18 *$ & -0.14 & $-0.20 *$ & $-0.19 *$ & $-0.34 * * *$ \\
\hline Male Sexual & $-0.36 * *$ & -0.22 & $-0.29 *$ & 0.06 & -0.20 & 0.00 & 0.03 & $-0.31 * *$ \\
\hline Female Sexual & $-0.71 * *$ & -0.10 & -0.21 & -0.28 & -0.24 & -0.25 & -0.10 & $-0.45^{*}$ \\
\hline Defecation Problems & $-0.53 * * *$ & $-0.59 * * *$ & $*-0.33 *=$ & 03 & 044 & 3 & $.20 *$ & $-0.64 * * *$ \\
\hline
\end{tabular}

$\dagger$ Sample size was 80 out of $124 ; \neq$ Sample size was 72 out of $83 ; \dagger \uparrow$ Sample size was 24 out of $41 ; * \mathrm{P}<0.05, * * \mathrm{P}<0.01, * * * \mathrm{P}<0.001$. 
Table 4. Discriminant validity

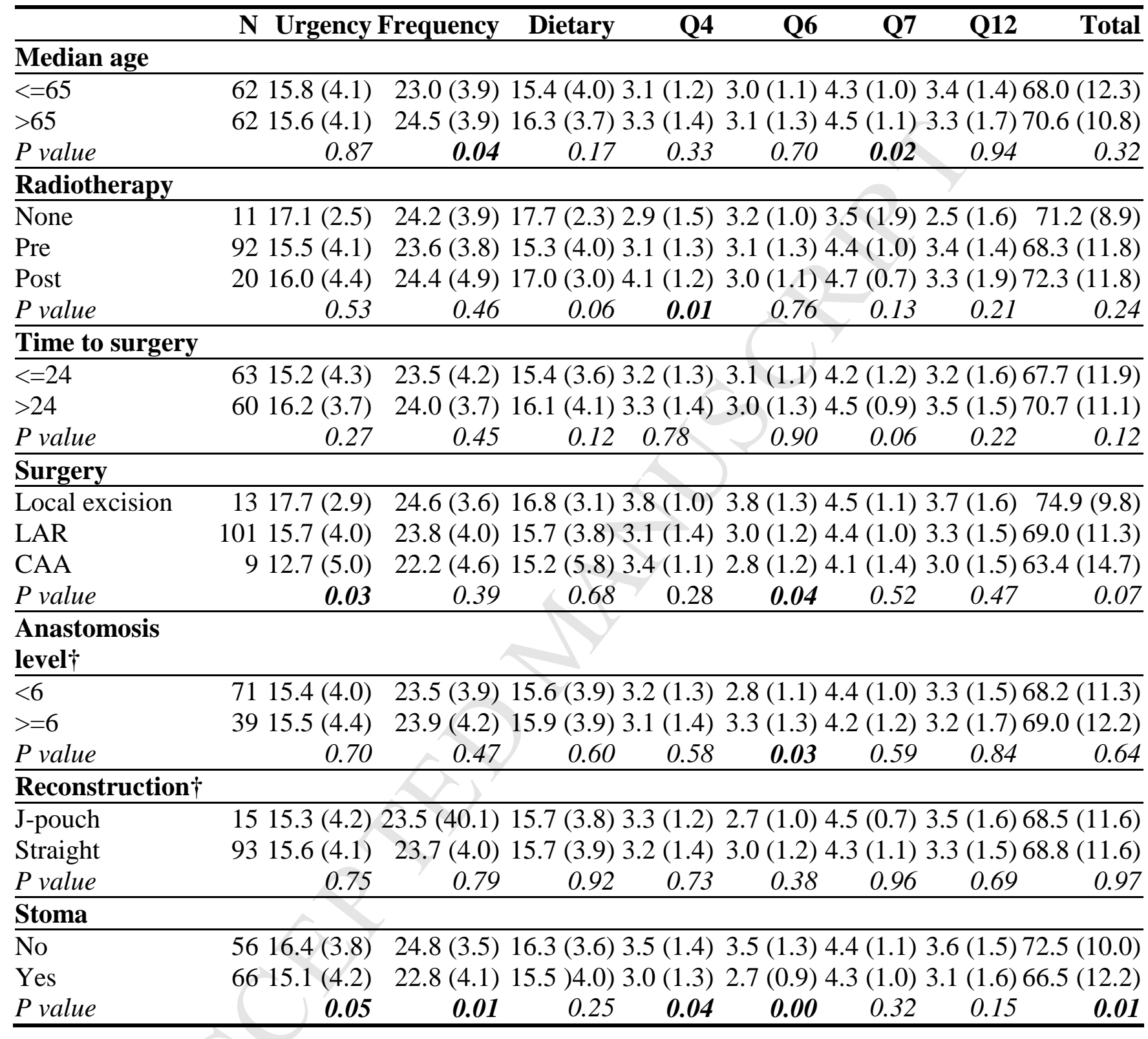

Values are reported as mean score (standard deviation). 